\title{
OSTEOGÉNESIS COMPARATIVA DE LOS CARTÍlAGOS SECUNDARIOS DE LA CLAVÍCULA Y PLACAS EPIFISIARIAS DE LOS HUESOS LARGOS
}

\author{
COMPARATIVE OSTEOGENESIS OF THE CLAVICLE SECONDARY CARTILAGES \\ AND EPIPHYSEAL CARTILAGES OF LONG BONES
}

\author{
M. Angélica Montenegro; Mariana Rojas \& Susana Domínguez
}

MONTENEGRO, M. A.; ROJAS, M. \& DOMíNGUEZ, S. Osteogénesis comparativa de los cartílagos secundarios de la clavícula y placas epifisarias de los huesos largos. Int. J. Morphol., 22(3):201-206, 2004.

RESUMEN: La clavícula es un hueso formado por osificación membranosa, es decir no se preforma de cartílago. Sin embargo desarrolla cartílagos secundarios como centros de crecimiento, los cuales presentan diferencias morfológicas y funcionales con los cartílagos de crecimiento de los huesos largos. Estos últimos son cartílagos primarios derivados del modelo cartilaginoso original.

Se realizó un estudio histológico e inmunohistoquímico de los cartílagos secundarios de la clavícula y de los cartílagos de crecimiento del fémur y húmero, en fetos humanos, entre las 12 y 40 semanas de gestación y en ratones entre 15 días de gestación y 20 días de edad. Se utilizaron las siguientes tinciones: hematoxilina-eosina-azul Alcián, tricrómico de Masson y rojo de picrosirius. En la técnica inmunohistoquímica de inmunoperoxidasa se utilizaron como anticuerpos primarios vimentina, PCNAy BMP.

Los cartílagos claviculares son cartílagos hialinos cubiertos por una delgada capa de tejido mesenquimático. En su superficie se distinguen varias capas: superficial de tejido conectivo, proliferativa formada por células mesenquimáticas, madurativa con condrocitos hipertróficos y una zona de osificación con condrocitos en regresión y trabéculas óseas en formación. El anticuerpo anti PCNA mostró inmunotinción positiva en la capa proliferativa en todas las etapas estudiadas y el anticuerpo anti BMP se expresó intensamente en las células de las zonas de osificación. La técnica de picrosirius mostró colágeno tipo I en las capas superficiales.

En los cartílagos claviculares la proliferación ocurre en el mesénquima de la capa proliferativa, en cambio, en los huesos largos la actividad mitótica ocurre en la zona de cartílago hiperplásico. En los cartílagos claviculares existe colágeno tipo I, a diferencia del cartílago de crecimiento epifisiario donde sólo existe colágeno tipo II.

Los cartílagos secundarios de la clavícula presentan importantes diferencias morfológicas y funcionales en el crecimiento con los cartílagos primarios de los huesos largos.

KEY WORDS: 1. Clavícula; 2. Cartílagos secundarios; 3. Placas epifisiarias.

\section{INTRODUCCIÓN}

Las articulaciones de la clavícula, esternoclavicular y acromioclavicular, son articulaciones sinoviales en las cuales las superficies articulares no están revestidas de un cartílago articular como el resto de las articulaciones sinoviales, sino que están revestidas por una capa fibrosa de tejido conectivo.

Estas articulaciones y la articulación témporomandibular, son las únicas que tienen sus superficies articulares cubiertas por tejido conectivo fibroso. La mandíbula y la clavícula son huesos formados por osificación membranosa, a partir de tejido mesenquimático, es de- cir, no tienen un modelo cartilaginoso previo como los huesos largos. En los huesos largos, el cartílago articular corresponde al cartílago remanente que persiste después de la osificación endocondral (Doskocit, 1985; Ogata \& Uhthoff, 1990; Wurgaft \& Montenegro, 2003).

La clavícula tiene un desarrollo variable en las distintas especies, de acuerdo al tipo de locomoción y movimientos de coordinación de los miembros anteriores. Así, en mamíferos que cavan, trepan o vuelan, la clavícula alcanza gran longitud, en cambio es reducida en animales que se apoyan y desplazan sobre sus 4 miembros. El grado de 
desarrollo y complejidad de la clavícula varía, siendo máximos en el hombre, en cambio en el perro y gato es un hueso vestigial, afuncional y no articulado y no existe en ovinos y felinos adultos (Doskocit; Ronning \& Kantomaa, 1988; Tran \& Hall, 1989; Rojas \& Montenegro, 1994, 1995; Hall, 2001).

La clavícula es el primer hueso en osificarse $\left(5^{\mathrm{a}}\right.$ a $6^{\mathrm{a}}$ semana de gestación), desarrollando cartílagos secundarios en ambas extremidades como centros de crecimiento. Las mandíbulas se osifican también tempranamente, casi junto con la clavícula y mucho antes que otras piezas del esqueleto y desarrolla el cartílago condilar que persiste hasta los 18 a 20 años.

Los cartílagos secundarios de la clavícula son cartílagos hialinos revestidos por una delgada capa de tejido mesenquimático que corresponde al pericondrio. Como todos los cartílagos, su matriz extracelular está constituida por una malla de fibrillas colágenas (tipos II, X y XI), proteoglicanos, glicoproteínas y agua. El principal proteoglicano es el agrecán, que consiste en un núcleo proteico al que están unidos muchos glicosaminoglicanos sulfatados del tipo condroitínsulfato y queratánsulfato. Estos proteoglicanos forman grandes complejos macromoleculares uniéndose con el ácido hialurónico. Los proteoglicanos son hidrofílicos y forman un gel que interactúa con el colágeno ocupando todo el espacio intersticial (Wurgaft \& Montenegro).

Estos componentes de la matriz cartilaginosa son continuamente sintetizados por los condrocitos y, al mismo tiempo son continuamente catabolizados. Sus productos de degradación van al líquido sinovial siendo fagocitados por las células de la membrana sinovial. De este modo, el mantenimiento normal de este tejido depende de un adecuado balance entre síntesis y degradación.

Estudios previos mostraron que el cartílago del cóndilo mandibular presenta características morfológicas y funcionales diferentes a las de la placa epifisiaria de los huesos largos (Wurgaft \& Montenegro). Esto nos motivó a realizar un estudio histológico e inmunohistoquímico de los cartílagos de crecimiento de la clavícula y compararlos con los cartílagos articulares y con las placas epifisiarias de los huesos largos.

\section{MATERIAL Y MÉTODO}

Se utilizaron 18 fetos humanos cuyas edades fluctuaron entre las 12 y 40 semanas de gestación y 15 ratones entre 15 días de gestación y 20 días de edad. En los fetos humanos se calculó la edad por las longitudes cráneo-glútea y cráneocalcánea y por las características externas. En los ratones, la edad de los embriones se determinó por la observación del tapón mucoso el cual se consideró como día 1 de gestación.

Se disecaron las clavículas, húmero y fémur de fetos humanos y de ratones, se fijaron en formalina tamponada al $10 \%$ y se decalcificaron en una solución de citrato de sodio y ácido fórmico. Se incluyeron en parafina y se realizaron cortes seriados sagitales de $6 \mu \mathrm{m}$, algunos de los cuales se tiñeron con hematoxilina-eosina-azul Alcián, tricrómico de Masson y picrosirius para observación selectiva del colágeno. Otros cortes se sometieron a la técnica inmuno-histoquímica de avidina-biotina-peroxidasa, utilizando como anticuerpos primarios: antivimentina, BMP-4 (proteína morfogenética de hueso) y PCNA (antígeno nuclear de proliferación celular).

La observación con luz polarizada de los cortes teñidos con pricrosirius, permite reconocer algunos tipos de colágeno. El colágeno tipo I se observa fuertemente birrefringente, con colores que varían del amarillo al rojo, en cambio el colágeno tipo III es menos refringente y aparece de color verde.

La vimentina es el principal componente de los filamentos intermedios de las células mesenquimáticas y de células derivadas de ellas.

El PCNA es un antígeno nuclear de proliferación celular, cofactor de la polimerasa delta, proteína esencial para la síntesis de ADN y que aparece en la etapa de síntesis del ciclo celular. Este anticuerpo muestra inmunotinción positiva en aquellas células que están al final de G1, se mantiene en S y desaparece después de G2. Es decir, todas las células que se tiñen, significa que están en el ciclo celular y las que no se tiñen están en G0, o sea en reposo.

Las BMP constityen una familia de factores de crecimiento que pertenecen a la superfamilia de los TGF- $\beta$. En los mamíferos existen al menos 12 BMPs, de las cuales la BMP-4 se expresa en el mesénquima condensado del esbozo de hueso, en el pericondrio, en el periostio, en los osteoblastos y en el cartílago hipertrófico. Además, la BMP4 es un morfógeno importante.

\section{RESULTADOS}

Los blastemas cartilaginosos de la clavícula humana aparecen entre las 10 y 12 semanas de gestación, en el tejido mesenquimático condensado de los extremos del esbozo clavicular y crecen rápidamente. Están rodeados de tejido mesenquimático que se continúa con el periostio. 


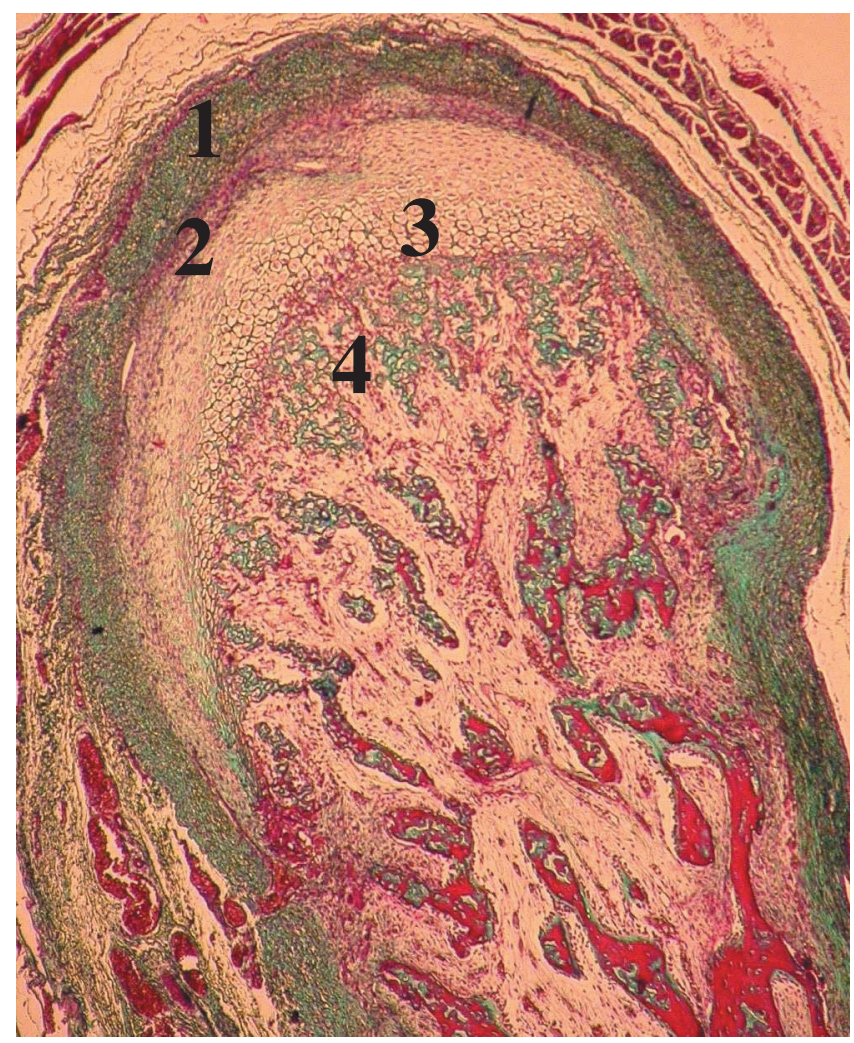

Fig.1. Corte histológico de clavícula de feto humano de 24 semanas. Se observan las capas superficial (1), proliferativa (2), madurativa (3) y la zona de osificación (4). Tinción: Tricrómica de Masson. 40X.

En los ratones, el cartílago secundario aparece a los 16 días de gestación.

Desde las 14 semanas de gestación, en la superficie de los cartílagos claviculares en desarrollo se pueden distinguir varias capas (Fig. 1):

- Una capa superficial formada por una cubierta de tejido conectivo, avascular, con pocos fibroblastos y algunas fibrillas colágenas dispuestas paralelamente a la superficie articular.

- Una zona proliferativa ubicada bajo la capa superficial formada por células mesenquimáticas indiferenciadas en activa proliferación. Estas células son vimentina, positivas.

- Una zona de maduración ubicada en el extremo profundo de la zona proliferativa formada por condrocitos hipertróficos. En esta zona, las células que provienen de la capa proliferativa se diferencian en condroblastos que elaboran proteoglicanos y colágeno tipo II para formar la matriz cartilagínea. Con el avance de la maduración, los condrocitos se hacen hipertróficos y luego degeneran debido a la calcificación de la matriz.

- Una zona de osificación, que tiene condrocitos y trabéculas óseas en formación. Se observa el proceso de osificación, la muerte de los condrocitos y lagunas vacías. Esta zona es invadida por vasos sanguíneos y osteoblastos que empiezan a sintetizar tejido óseo.

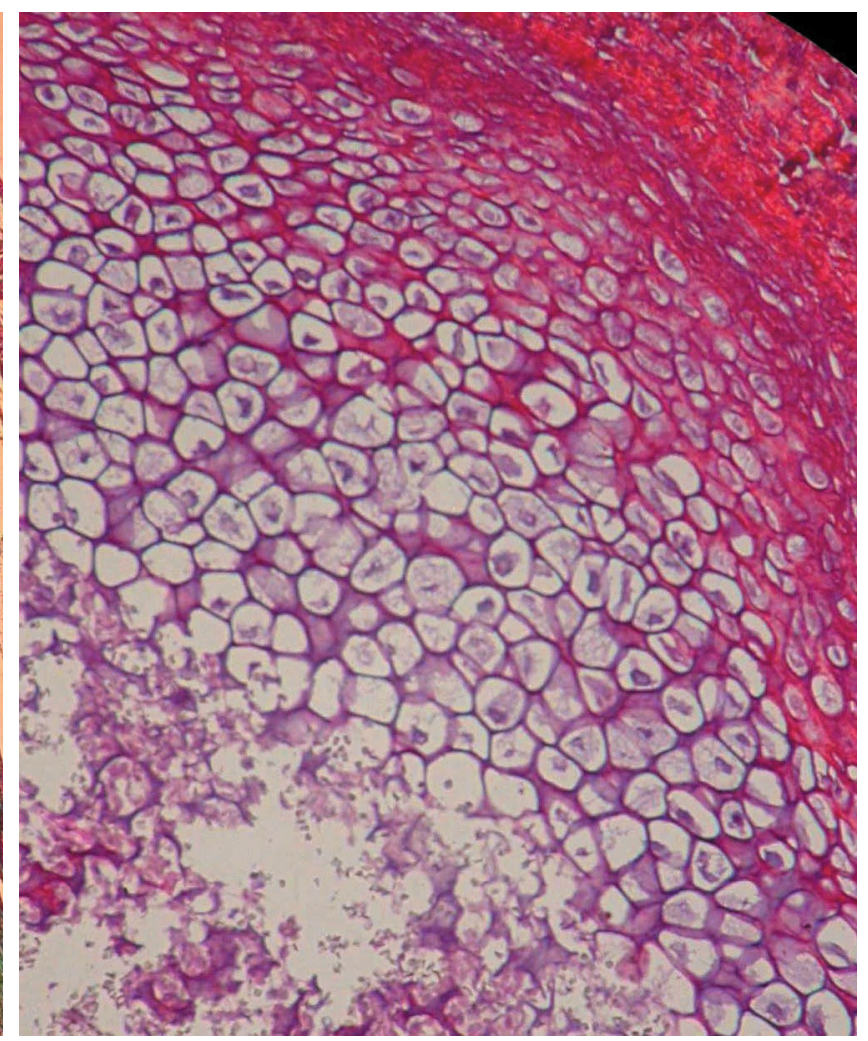

Fig. 2. Se observa colágeno tipo I fuertemente birrefringente en las capas superficial, proliferativa y madurativa de un cartílago clavicular en feto humano de 28 semanas. Tinción, Picrosiriuspolarización. 200X.

En ratones, las clavículas en crecimiento muestran las mismas capas.

La observación con lentes polarizadores de los cortes teñidos con picrosirius, mostró en las clavículas humanas y de ratón, colágeno tipo I en la matriz extracelular de las capas fibrosa y proliferativa y también en la capa madurativa donde aparece fuertemente birrefringente con colores que varían del amarillo al rojo. La matriz ósea de la zona de osificación mostró también fuerte birrefrigencia (Fig. 2). En las placas de crecimiento del fémur y del húmero, en cambio, no se observó birrefringencia indicadora de colágeno tipo I.

En los cartílagos claviculares humanos y de ratón se observaron amplios canales que contienen vasos sanguíneos y que cruzan perpendicularmente el cartílago, conectando directamente con la zona de osificación (Fig. 3).

El anticuerpo antiPCNA mostró inmunotinción positiva en la capa proliferativa de las clavículas y en el cartílago hiperplásico de húmero y fémur, tanto de fetos humanos como de los ratones, en todas las etapas estudiadas (Figs. 4 y 5).

La BMP se expresó intensamente en las zonas de osificación como el periostio, osteoblastos y cartílago hipertrófico, tanto en las clavículas como en los huesos largos de fetos humanos y de ratones (Fig. 6). 


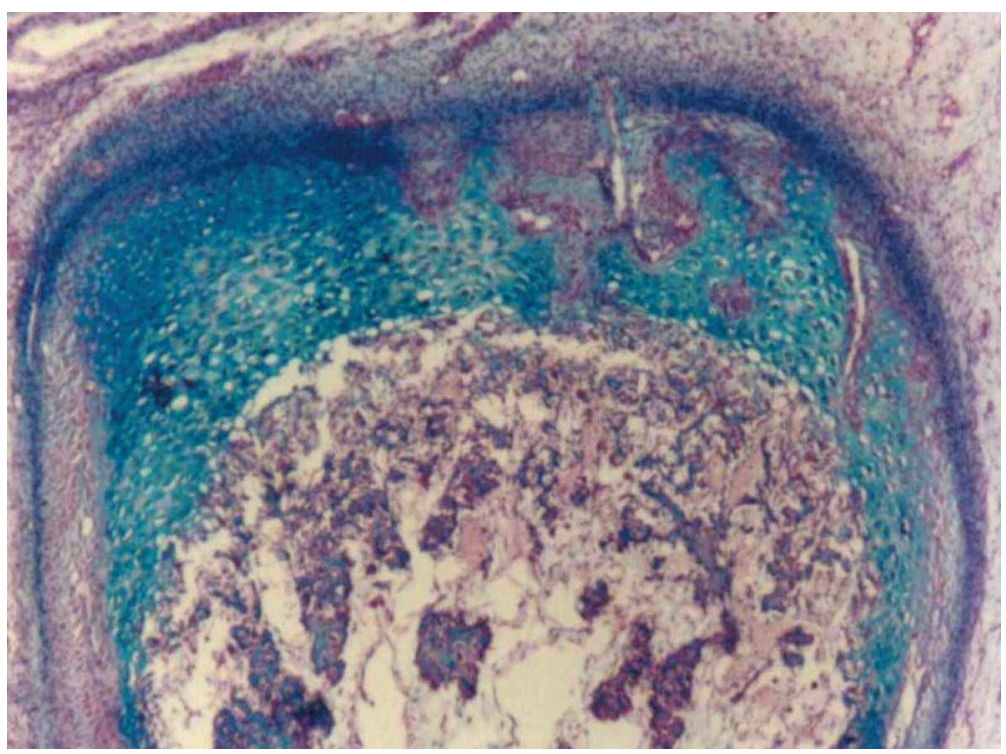

Fig. 3. Se observan canales vasculares en el cartílago secundario de la clavícula de un feto humano de 14 semanas. Tinción: Hematoxilina- Eosina-Azul de Alcián. 40X

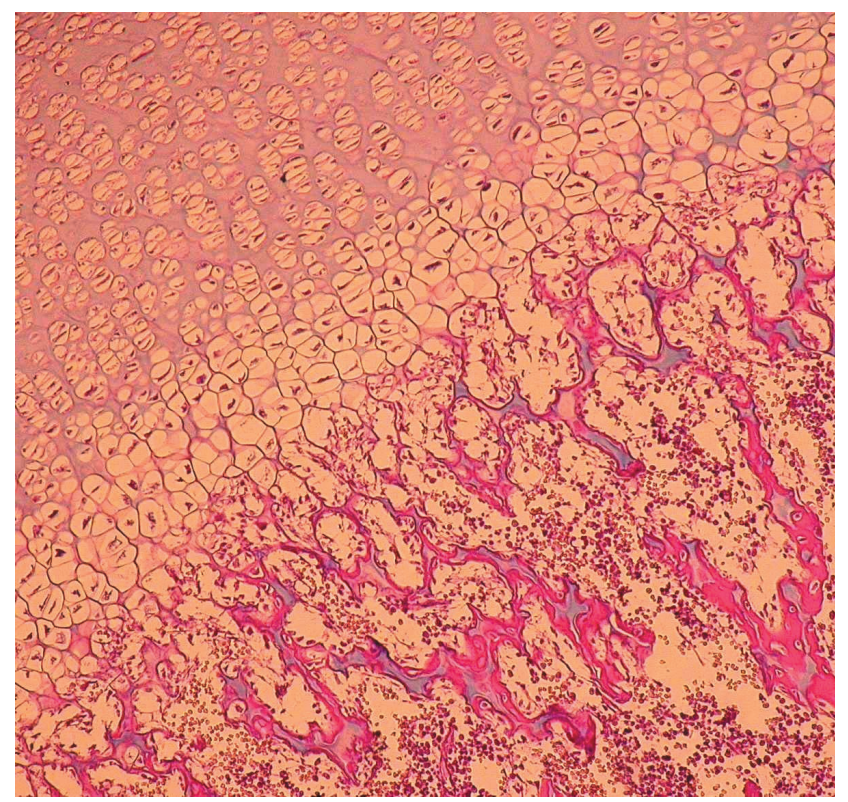

Fig. 4. Se muestra el cartílago de crecimiento del húmero de un feto humano de 22 semanas. Tinción: Hematoxilina-Eosina. 100X.

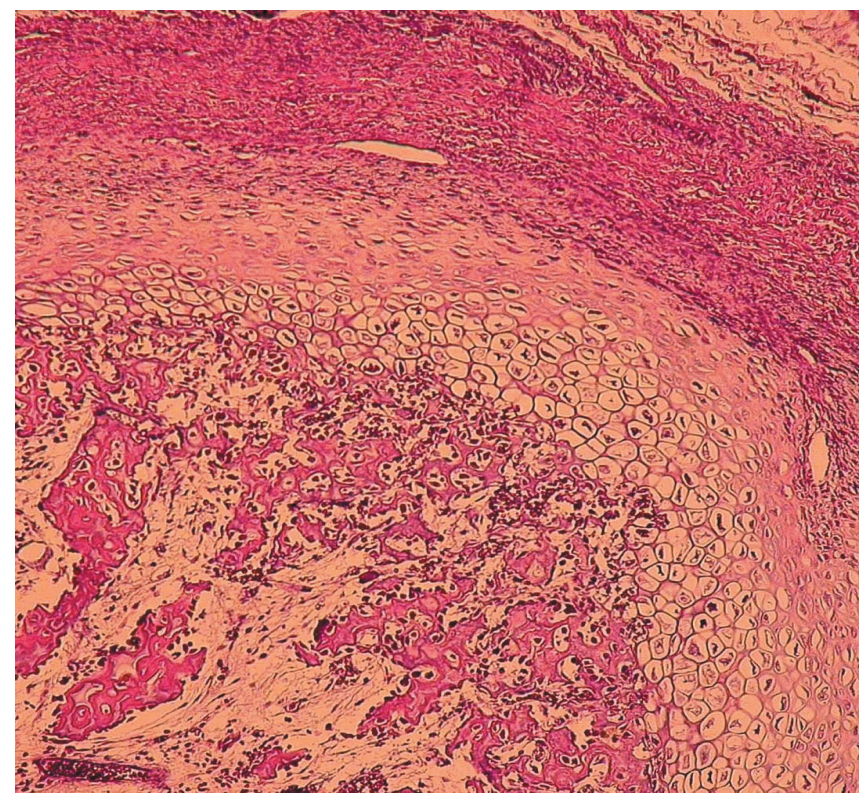

Fig. 5. Se observa el cartílago secundario de la clavícula del mismo feto de la figura anterior. Tinción: Hematoxilina-Eosina. 100X.

\section{DISCUSIÓN}

El análisis de nuestros resultados muestra que los cartílagos de crecimiento de la clavícula presentan características particulares que son similares a las que se observan en el cartílago del cóndilo mandibular, pero al mismo tiempo, son diferentes de lo que ocurre en los cartílagos articulares y en las placas epifisiarias de los huesos largos.

Se sabe que los cartílagos de crecimiento de la clavícula son cartílagos secundarios ya que se desarrollan del tejido mesenquimático que forma el esbozo del hueso, a diferencia de los cartílagos de crecimiento y articulares de los huesos largos que son cartílagos primarios que derivan del molde cartilaginoso original (Wurgaft \& Montenegro).
Una de las mayores diferencias radica en el hecho que en los cartílagos claviculares, la proliferación celular ocurre en el tejido conectivo de la capa proliferativa y estas células no forman columnas, en cambio en los huesos largos, la actividad mitótica ocurre en la zona de cartílago hiperplásico, a partir de condrocitos en reposo, donde originan los grupos isógenos axiles (Fig. 7).

Se ha demostrado que la actividad proliferativa de la clavícula se detiene alrededor de los 25 años, pero algunas células persisten y el cartílago situado bajo ellas se transforma en fibrocartílago (Doskocit). 


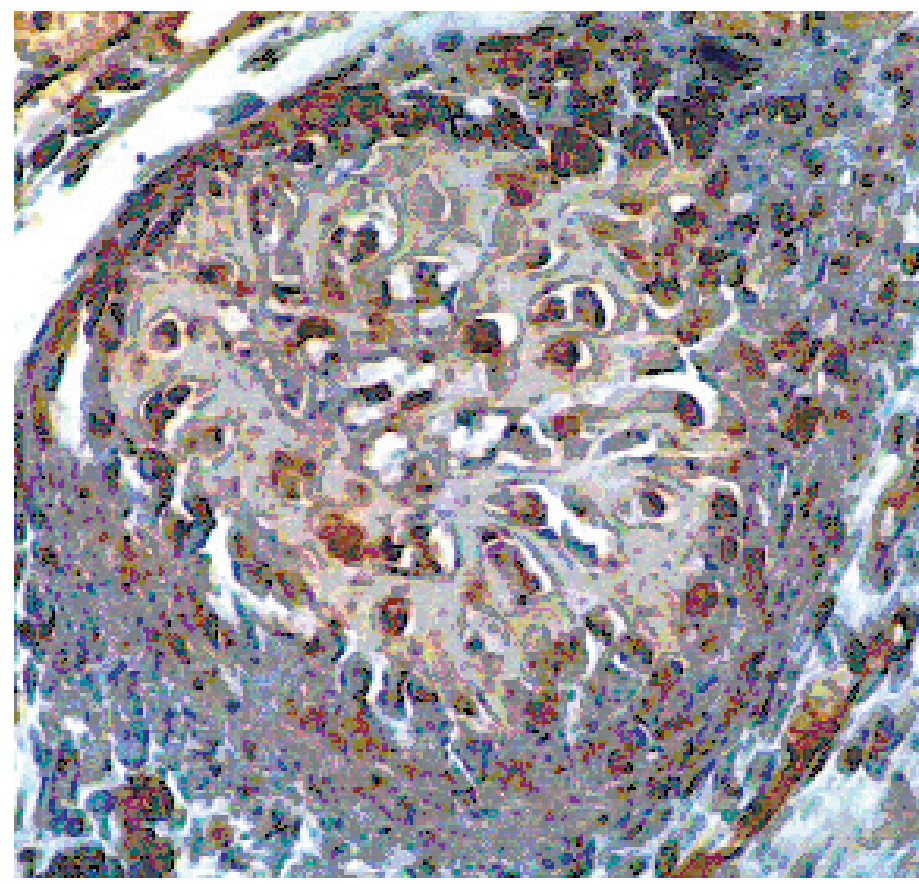

Fig. 6. BMP-4 en una clavícula de ratón de 10 días de edad. Se observa inmunotinción positiva en los osteoblastos. 200X.

Los canales vasculares que cruzan el cartílago perpendicularmente llegando directamente a la zona de osificación, han sido descritos también en el cóndilo mandibular con las mismas características, donde parecen cumplir una función nutricia para el cartílago (Berraquero et al., 1995; Wurgaft \& Montenegro).

La técnica de picrosirius-polarización muestra que además del colágeno tipo II, existe gran cantidad de colágeno tipo I en las capas superficial, proliferativa y madurativa de los cartílagos claviculares. En las placas de crecimiento del fémur y del húmero no existe colágeno tipo I, sino colágeno tipo II. La presencia de cartílago tipo I en la matriz extracelular de las capas fibrosa, proliferativa y de cartílago hipertrófico, ha sido también demostrada en las articulaciones témporomandibulares de ratón (Mizoguchi et al., 1990) y humana (Wurgaft \& Montenegro).

Estudios experimentales en ratones transgénicos con mutaciones del colágeno tipo II, mostraron que los cambios que se producen en los cartílagos secundarios del cóndilo mandibular y la clavícula, son menos pronunciados que los que afectan a los cartílagos primarios de los huesos largos, por lo cual se sostiene que el papel del colágeno tipo II en mantener la integridad estructural, es menos importante en los cartílagos secundarios que en los primarios (Rintala et al., 1996).

La expresión de BMP-4 observada en las clavículas de los fetos humanos y de ratón, es similar a la del fémur y húmero, lo que indica que el proceso de osificación a partir de los condrocitos hipertróficos tiene características similares en ambos casos. Además, estas mismas características se han observado en la ATM (Wurgaft \& Montenegro).

La BMP regula la expresión del factor de transcripción Sox 9, el cual es necesario para la diferenciación de los condrocitos y del colágeno (Bi et al., 1999; Healy et al., 1999).

En pollo y ratón, se ha demostrado que el mayor estímulo para el crecimiento del cartílago clavicular, es biomecánico basado en la actividad muscular (Hall, 1986; Tran \& Hall).

Algunas evidencias experimentales indican que, durante el crecimiento de la clavícula y del cóndilo mandibular, existe una respuesta diferente a factores hormonales y metabólicos con respecto a lo descrito para los huesos largos.
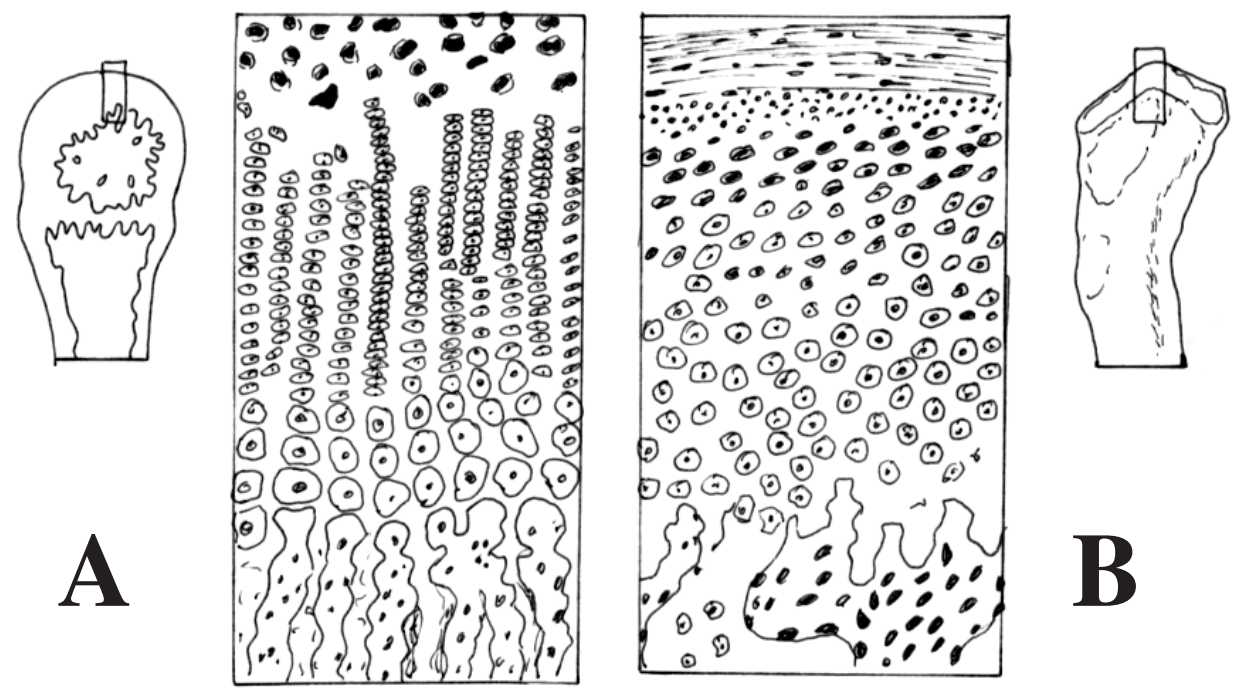

Fig. 7. Diagrama de los cartílagos articulares en crecimiento de un hueso largo (A) y de la clavícula (B). 
MONTENEGRO, M. A.; ROJAS, M. \& DOMínGUEZ, S. Comparative osteogenesis of the clavicle secondary cartilages and epiphyseal cartilages of long bones. Int. J. Morphol., 22(3):201-206, 2004.

SUMMARY: The clavicle arises by intramembranous ossification, but it develops secondary cartilages as growth centers. These are different in their histologic organization with long bone epiphyseal growth plates. The purpose of this study was to evaluate histologically the secondary cartilages of the clavicle in human fetus and young mice and compare them with that in the long bone growth plates.

The clavicles and long bones were fixed in buffered 10\% formalin, decalcificated, embedded in paraffin wax, serially sectioned at $6 \mathrm{~mm}$ thickness and stained with hematoxylin-eosin and Alcian blue, Masson and Picrosirius-polarization methods. Some sections were subjected to the immunoperoxidase technique using vimentin, BMP (bone morphogenetic protein) and PCNA (proliferated cellular nuclear antigen) as primary antibodies.

The surface of the clavicular cartilage presents several zones: an articular layer of connective tissue, a proliferative layer with undifferentiated mesenchymal cells, the madurative layer with hypertrophic chondrocytes, and an erosion and ossification zone with bone trabeculae. In clavicular cartilage, type I collagen was present not only in the extracellular matrix (ECM) of the fibrous and proliferative layers, but also in the ECM of the madurative layer. In the growth plate, type I collagen was nor present in the cartilage but in the perichondrium, periostium and bone matrices.

Clavicular chondroblasts arise from undifferentiated connective cells and these chondroblasts are not aligned in columns that characterizes growth plates. Another histologic difference is the existence in the clavicle of vascular canals that cross cartilage perpendicularly and connect with the erosion zone.

The secondary cartilages of the clavicle present important morphologic differences with the primary cartilages of long bones, but similar to that observed in the condylar cartilage of the mandible.

KEY WORDS: 1 . Clavicle; 2 . Secondary cartilages; 3 . Growth cartilages.

\section{REFERENCIAS BIBLIOGRÁFICAS}

Berrraquero, R.; Palacios, J.;Gamallo, C.; Dela Rosa, P.; \& Rodriguez, J.I. Prenatal growth of the human mandibular condylar cartilage. Am. J. Orthod. Dentofac. Orthop., 108: 194-200, 1995.

Bi, W.; Deng, J.; Zhang, Z.; Bheringer R.R. \& De Crombrugghe, B. Sox 9 is required for cartilage formation. Nat. Gen., 22: 85-9, 1999.

Doskocit, M. The development of the clavicle in man. Gegenbaurs Morphol. Jahrb., 131:357-65, 1985.

Hall, B.K. The role of movement and tissue interactions in the development and growth of bone and secondary cartilage in the clavicle of the embryonic chick. J. Embryol. Exp. Morphol., 93:133-52, 1986.

Hall, B.K. Development of the clavicles in birds and mammals. Review J. Exp. Zool., 289: 153-61, 2001.

Healy, C.; Uwanogho, D. \& Sharpe, P. T. Regulation and the role of Sox 9 in cartilage formation. Dev. Dyn., 215: 69-78, 1999.

Mizoguchi, I.; Nakamura, N.; Takahashi, I.; Kagayama, M. \& Mitani, H. An immunohistochemical study of localization of type I and type II collagens mandibular condylar cartilage compared with tibial growth plate. Histochemistry, 93:593-9, 1990.

Ogata, S. \& Uhthoff, H. K. The early development and ossification of the human clavicle. An embryologic study. Acta Orthop. Scand., 61:330-4, 1990.
Rintala, M.; Metsarante, M.; Vuorio, E. \& Rönning, O. Abnormalities in secondary cartilages in fine lines of transgenic mice harboring two different types of mutations in cartilagespecific type II collagen gene. J. Craniofac. Genet. Dev. Biol., 16: 148-55, 1996.

Rojas, M. \& Montenegro M.A. Embriogénesis del área clavicular en la oveja (Ovis aries) y gato (Felis catus). Rev. Chil. Anat., 12:5-11, 1994.

Rojas, M. \& Montenegro M.A. An anatomical and embryological study of the clavicle in cats (Felis domesticus) and sheep (Ovis aries) during the prenatal period. Acta Anat. 154:128-34, 1995.

Ronning, O. \& Kantomaa, T. The growth pattern of the clavicle in the rat. J. Anat. 159:173-9, 1988.

Tran, S. \& Hall, B.K. Growth of the clavicle and development of clavicular secondary cartilage in the embryonic mouse. Acta Anat., 135:200-7, 1989.

Wurgaft, R. \& Montenegro, M. A. Desarrollo y estructura de la articulación témporomandibular. Santiago, Servimpres, 2003.

Dirección para correspondencia:

Prof. Dra. M. Angélica Montenegro

Programa de Morfología, ICBM

Facultad de Medicina

Universidad de Chile

Independencia 1027,

Clasificador 7, Correo 7,

Santiago - CHILE

Email:mmontene@med.uchile.cl

Recibido : 28-05-2004

Aceptado: 22-07-2004 